\title{
MINAT STUDI LANJUT: Tinjauan Kritis dari Sudut Pandang Partnership Governance dan Tingkat Sosial Ekonomi Masyarakat
}

\author{
Mashudi1), Luluk Fauziah ${ }^{2)}$, Endang Larasati ${ }^{3)}$, Sri Suwitri ${ }^{4)}$, dan \\ Ida Hayu Dwimawanti ${ }^{5)}$
}

\author{
1)Sekolah Vokasi Universitas Diponegoro Semarang \\ emashud_bli@yahoo.co.id \\ ${ }^{2}$ Sekolah VokasiUniversitas Diponegoro Semarang \\ lulukfauz@yahoo.co.id \\ ${ }^{3)}$ Fakultas IImu SosiaL dan IImu Politik Universitas Diponegoro Semarang \\ endanglarasatiprof57@gmail.com \\ 4)Fakultas IImu SosiaL dan IImu Politik Universitas Diponegoro Semarang \\ prof.suwitri62@gmail.com \\ 5)Fakultas IImu SosiaL dan IImu Politik Universitas Diponegoro Semarang \\ ida2hade@gmail.com
}

\begin{abstract}
Abstrak
Berangkat dari kondisi yang berupa rendahnya Angka Partisipasi Kasar (APK) dan rendahnya Indeks Pembangunan Manusia (IPM), maka penelitian ini bertujuan untuk mengetahui tingkat kemitraan antara pemerintah dengan masyarakat dan tingkat sosial ekonomi masyarakat dalam mendorong para tamatan sekolah untuk melanjutkan sekolah ke jenjang yang lebih tinggi dan mendiskripsikan faktor penghambat dan pendukung dalam peningkatan APK.

Dalam penelitian ini pendekatan yang digunakan adalah pendekatan kualitatif sedangkan format penelitiannya adalah format deskriptif. Informan dalam penelitian ini adalah para aktor dan pemangku kepentingan (stakeholders) dalam peningkatan APK dan peningkatan IPM yang ditentukan secara purposive. Tehnik pengumpulan datanya adalah focus group discussion (FGD) dan dibantu oleh teknik pengumpulan data dokumentasi, wawancara, maupun observasi.

Temuan penelitian ini sebagai berikut: kemitraan antara pemerintah dengan masyarakat dalam peningkatan APK sudah berjalan, namun perlu upaya-upaya peningkatan. Faktor pendukung upaya peningkatan APK adalah menggeliatnya industri rumahan yang menyokong dari sisi ekonomi untuk melanjutkan studi ke jenjang yang lebih tinggi.
\end{abstract}

Kata kunci: partnership, governance, studi lanjut, dan sosial ekonomi.

\begin{abstract}
Departing from the issue of low conditions depicted in the Gross Enrollment Rate (APK) and Human Development Index (HDI), this study aims to determine the level of partnership among the government, community, and the socio-economic level of the community in encouraging school graduates to continue to higher levels of study as well asto describe the inhibiting and supporting factors in increasing APK.

A qualitative approach is employed while the research format is a descriptive study. The informants in this study were the actors and stakeholders in increasing the APK and HDI which weredetermined purposively. The technique of data collection is focus group discussion (FGD) and is assisted by documentation of data collection techniques, interviews, and observations.

The findings of this study portray that the partnership between the government and the community in increasing the APK has been running, but it requires improvement efforts. The supporting factor in the attempt to increase the APK includes the development of the home industry which simultaneously triggers the economic level and further study interest to a higher level.
\end{abstract}

Keywords: partnership, governance, further study, socio-economic level

\section{PENDAHULUAN}

Abad XXI merupakan abad globalisasi. Abad globalisasi bisa dipandang sebagai abad perluasan peluang, walaupun juga di sertai adanya ancaman. Mengingat masih adanya peluang, dan jika tidak ingin tertinggal dalam percaturan ekonomi dunia, maka tidak ada alasan lain untuk tidak ikut bermain di arena 
global. Naisbitt, J. \& Aburdane, P. (1990) menyatakan setiap negara yang berusaha untuk tinggal tertutup secara ekonomi dan terpisah dari permainan global akan tertinggal tanpa ada harapan di belakang. Era global dapat dipandang sebagai era persaingan kualitas terutama dalam pemanfaatan teknologi informasi dan komunikasi (Information and Communication Technology, ICT) sebagai fasilitas bagi sumber daya manusia (SDM) untuk mempertahankan keberlanjutan suatu lembaga (Jarboe, 2005; Sahney, Fawcett, Rhoads \& Burnah, 2004; Mangundayao, 2003). Kenyataan ini membawa berbagai konsekwensi baru pada berbagai bidang, termasuk bidang pendidikan. Konsekwensi baru ini antara lain adanya tuntutan terhadap berbagai lembaga pendidikan, baik lembaga pendidikan formal, non formal, maupun lembaga pendidikan informal dalam keluarga. Lembaga-lembaga pendidikan tersebut dituntut untuk menghasilkan lulusan yang berkualitas dan mampu memenuhi permintaan pasar kerja, dimana penguasaan berbagai teknologi baru dan ketrampilan baru semakin dituntut (Lievens, van Dam \& Anderson, 2002).

Dengan demikian, era global dapat dipandang sebagai era semakin besarnya peluang, semakin ketatnya persaingan dan selanjutnya mutu menjadi hal yang penting, baik mutu input, mutu proses maupun mutu output. Untuk menghadapi kondisi tersebut diperlukan SDM yang berkualitas, kreatif dan yang inovatif. Kondisi SDM yang demikian itu dapat ditempuh melalui pendidikan. Hal ini sesuai dengan pernyataan Chirkov, V. et al. (2007), bahwa dengan memperoleh pendidikan yang baik, seseorang akan lebih memiliki kesempatan untuk meningkatkan karier. Karatape, M.O. et al. (2005) juga menyatakan bahwa semakin tinggi tingkat pendidikan seseorang, semakin tinggi tingkat usahanya dan semakin tinggi sifat berkompetisinya yang selanjutnya semakin tinggi kinerjanya. Demikian juga Lanzi, D. (2007), menyatakan bahwa pendidikan akan meningkatkan kemampuan dan ketrampilan seseorang, yang selanjutnya akan berdampak langsung pada peningkatan kualitas hidup dan peningkatan kualitas berekonomi/berproduksi. Hal itu sesuai dengan slogan "Education for all". Dimov, P.D. \& Shepherd, A.D. (2005) menyatakan bahwa semakin spesifik pendidikan, semakin tinggi kinerja seseorang dalam jabatannya. Pidarta, M. (2000) juga menyatakan bahwa mendidik bermaksud meningkatkan hidupnya dari kehidupan alamiah menjadi berbudaya. Mendidik adalah membudayakan manusia.

Tuntutan dihasilkannya SDM yang berkualitas, kreatif, dan inovatif sesuai dengan permintaan pasar tenaga kerja, sebagai konsekwensi logis dari era persaingan mutu tersebut tampaknya tidak dapat ditunda-tunda lagi, karena pada era globalisasi ini SDM dipandang sebagai sumberdaya utama dari competitive advantage baik pada bidang pendidikan maupun bisnis (Colff, 2004; Karami, Farhad \& Cusworth, 2004) dan merupakan faktor kunci dalam reformasi ekonomi (Didin, 2003). Namun demikian, hanya SDM yang mampu menunjukkan kinerja pada level yang tinggi dalam sistem kerja yang baik yang dapat meningkatkan competitive advantage tersebut (Datta, Guthrie, Wright, 2005). Dengan demikian tidaklah berlebihan jika dikatakan bahwa untuk menghadapi era globalisasi, SDM yang mampu bersaing memang mutlak diperlukan (Jones, 2004; Salladien, 2002; 1996). Untuk memenuhi tuntutan tersebut, hampir setiap pihak yang berkepentingan menyandarkan harapannya pada instansi atau lembaga yang menyelenggarakan pendidikan. Mereka mengharapkan agar lembaga pendidikan benar-benar mampu menghasilkan SDM yang bermutu yang mampu bersaing dan mampu memainkan perannya baik sebagai strategic partner, administrative expert, employee champion maupun change agent sebagaimana yang dikemukakan oleh Conner \& Ulrich (Refius Pradipta Setyanto, 2004).

Pendidikan, merupakan investasi SDM. Karena untuk menciptakan SDM yang berkualitas, kreatif, dan inovatif memerlukan biaya yang besar dan biaya besar yang telah dikeluarkan tersebut tidak bisa dikembalikan dengan segera. Padahal tidak setiap orang tua memiliki dana yang cukup untuk membiayai sekolah anaknya. Anak yang orang tuanya secara ekonomi baik saja yang berhasil sekolahnya. Hal ini sesuai dengan temuan Wronka, I. \& Chmara, P.R. (2006) bahwa tingkat status sosial ekonomi orang tua memiliki korelasi positif dengan frekuensi kehadiran anak di sekolah. 
Temuan Brown, W.A. et al. (2007) menekankan kepada para orang tua akan pentingnya investasi pada SDM, bahwa investasi pada SDM melalui pendidikan akan meningkatkan kinerja organisasi, dan kinerja organisasi akan meningkat sesuai dengan peningkatan investasi di SDM. Lin, W.B. (2007) juga menyatakan bahwa investasi pada SDM mempunyai kontribusi pada terciptanya kreatifitas yang selanjutnya berpengaruh positif terhadap kinerja usaha. Selanjutnya Bae, J. \& Rowley, Chris (2004) menyatakan bahwa semakin tinggi tingkat pengembangan SDM akan membawa dampak positif pada kinerja perusahaan.

UNESCO menyatakan bahwa pendidikan ibarat investasi SDM. Pidarta, Made : 2007 menyatakan bahwa pendidikan merupakan investasi tidak langsung dalam proses produksi. Ini berarti bagi keluarga yang ekonominya semakin bagus, ada kecenderungan menyekolahkan anaknya ke jenjang yang lebih tinggi semakin besar. Namun faktanya tidak selalu demikian.
Artinya terdapat kersenjangan dalam fenomena pendidikan. Hal ini juga terdapat ketidaksesuan dengan apa yang dinyatakan oleh Todaro dan Smith (2003) bahwa orang tua yang mempunyai kesempatan dan pendidikan atau latihan yang diperlukan untuk memperoleh pekerjaan tetap yang mapan dan berpenghasilan tinggi, mereka bisa dengan mudah menyediakan pangan, sandang, papan dan pendidikan bagi anakanak mereka. Dengan merujuk pada pendapat Todaro tersebut, jika orang tua berpenghasilan tinggi, semestinya pendidikan anaknya juga tinggi. Namun, menurut hasil studi pendahuluan yang dilakukan oleh peneliti melalui wawancara dan observasi di lapangan, yang terjadi tidak selalu demikian. Hal itu juga sesuai dengan pendapat Todaro berikutnya, yang dinyatakan bahwa kita tidak dapat memastikan bahwa peningkatan pendapatan akan diinvestasikan ke dalam pendidikan dan kesehatan anak-anak secara memadai.

Gambar 1.1 Indeks Pembangunan Manusia Kabupaten/ Kota Provinsi Jawa Tengah

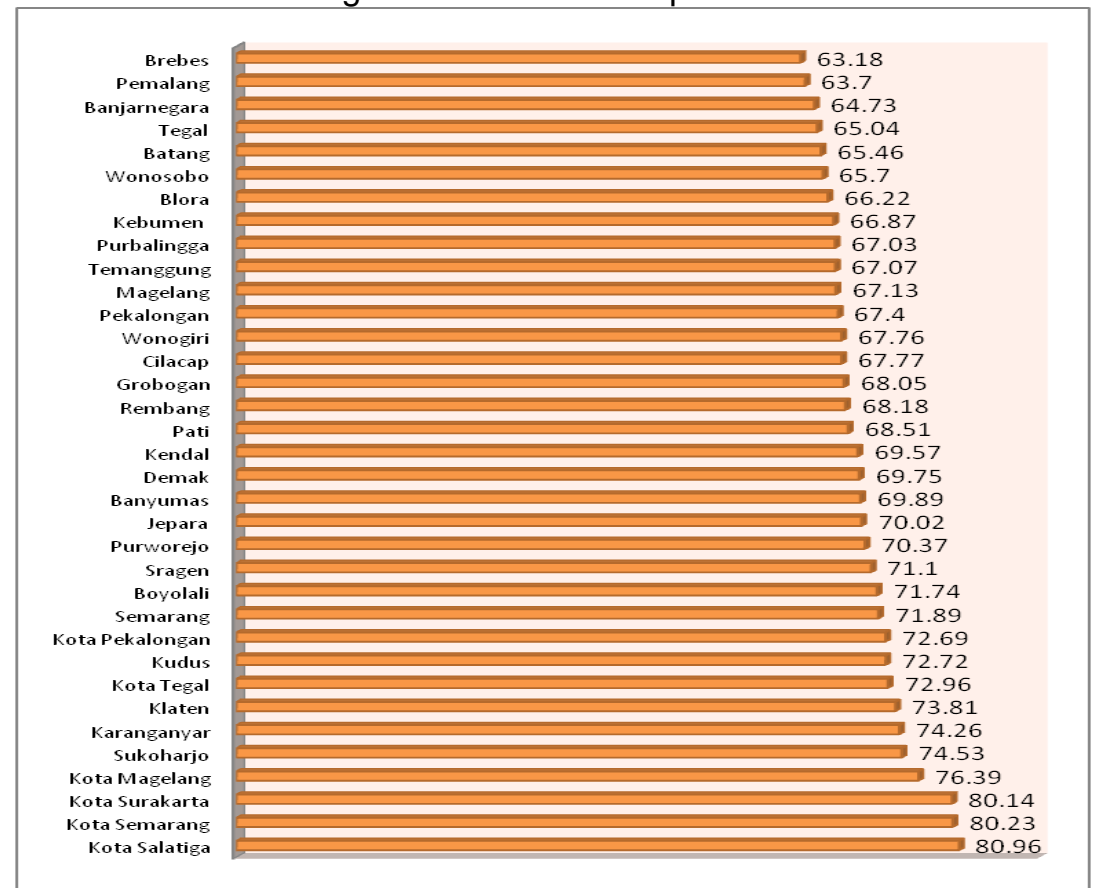

Sumber: Jawa Tengah Dalam Angka, 2016.

Dengan mengamati Gambar 1.1. di atas dapat dinyatakan Indeks Pembangunan Manusia dari Kabupaten/ Kota di Provinsi Jawa Tengah yang terrendah adalah Kabupaten Brebes dengan Indeks sebesar 63,18. Kemudian IPM Kabupaten Pemalang sedikit di atas Kabupaten Brebes, dengan indeks sebesar 63,70. Dibandingkan dengan Kabupaten/Kotadi Provinsi Jawa Tengah, IPM Kabupaten Pemalang berada pada posisi ke 34 dari 35 Kabupaten/Kota. Rendahnya Indeks Pembangunan Manusia (IPM) di Kabupaten 
Pemalang diduga disebabkan oleh 3 (tiga) dimensi dasar yang digunakan untuk mengukur IPM yaitu: kesehatan yang diwakili oleh Angka Harapan Hidup Saat Lahir, pendidikan yang diwakili oleh Angka Harapan Lama Sekolah (Expected Years Schooling) dan Rata-rata Lama Sekolah (Mean Years Schooling), dan standar hidup layak yang diwakili pengeluaran atau daya beli masyarakat masih rendah. Saat ini pencapaian Angka Harapan Hidup, Expected Years Schooling, Mean Years Schooling, secara keseluruhan Kabupaten Pemalang pencapaiannya masih dibawah rata-rata dan belum bisa melampui pencapaian Provinsi Jawa Tengah. Dimana Angka Harapan Hidup (AHH) di Kabupaten Pemalang sebesar 72,77 sedangkan di Provinsi Jawa Tengah Angka Harapan Hidupnya (AHH) sudah mencapai 73,96. Kemudian Angka Harapan Lama Sekolah (EYS: Expected Years Schooling) di Kabupaten Pemalang sebesar 11,86 sedangkan pencapaian di Provinsi Jawa Tengah telah mencapai 12,38.

Gambar 1.2 Tiga Kabupaten di Provinsi Jawa Tengah Yang Memiliki Indeks MYS Terendah.

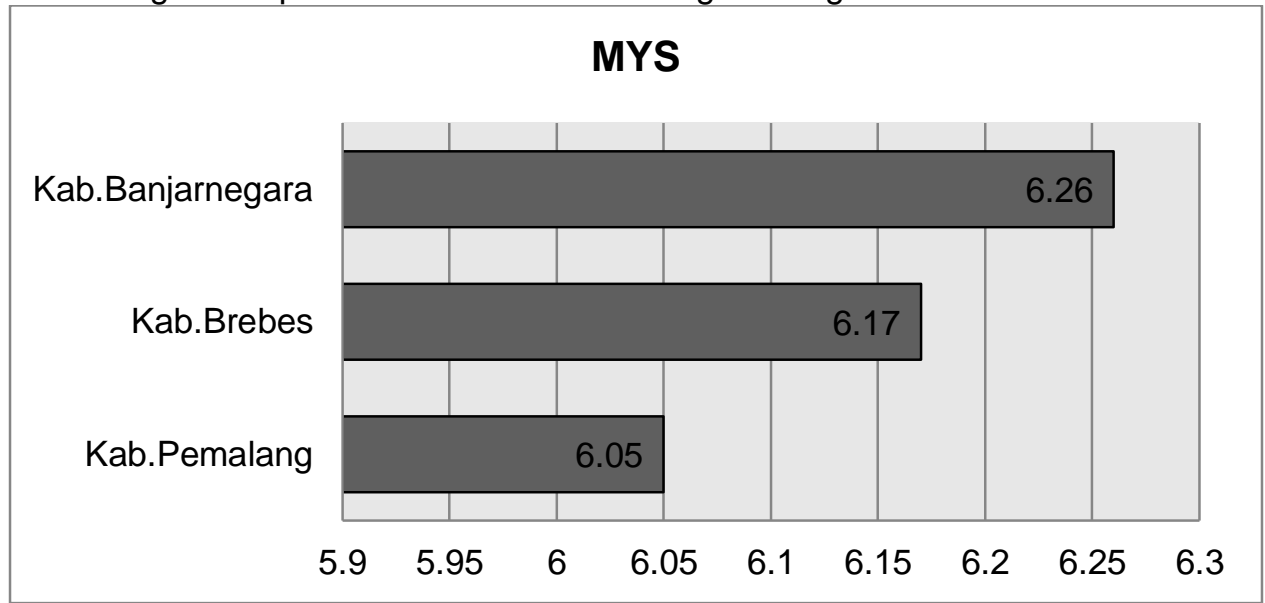

Sumber: Jawa Tengah Dalam Angka, 2017

Dengan mengamati gamnbar 1.2 di atas dapat dinyatakan rata-rata Lama Sekolah (MYS: Mean Years Schooling) penduduk di Kabupaten Pemalang juga masih sangat rendah hanya sebesar 6,05 sedangkan ratarata pencapaian di Provinsi Jawa Tengah sudah mencapai 7,03. Rendahnya pencapaian Angka Harapan Hidup (AHH) setelah lahir, Angka Harapan Lama Sekolah (EYS: Expected Years Schooling) Rata-rata Lama Sekolah (MYS: Mean Years Schooling) di Kabupaten Pemalang, juga diikuti oleh rendahnya standard hidup layak (decent standard of living) yang ada di Kabupaten Pemalang. Dari ketiga indikator penilaian IPM berdasarkan data di atas dapat diketahui bahwa dua indikator penilaian IPM di Kabupaten Pemalang yaitu Indeks Ukuran Daya Beli masyarakat dan Rata-rata Lama Sekolah merupakan dua indikator yang terendah, jika dibandingkan dengan dua kabupaten lainnya di Jawa Tengah. Sehingga penelitian tentang minat studi lanjut : tinjauan kritis dari sudut pandang partnership governance dan tingkat sosial ekonomi masyarakat di Kabupaten Pemalang penting dilakukan.

Berdasarkan latar belakang masalah sebagaimana dijelaskan di atas, maka rumusan masalah penelitian ini sebagai berikut: bagaimanakah tingkat kemitraan antara pemerintah dengan swasta dalam peningkatan APK?; serta bagaimanakah tingkat social ekonomi dalam mendorong peningkatan APK?

\section{TINJAUAN PUSTAKA}

\section{Konsep Governance}

United Nations Development Programme (UNDP): "Governance is defined as the exercise of political, economic and administrative authority to manage a nation's affairs. (Governance sebagai pelaksanaan kewenangan politik, ekonomi, dan administrasi dalam mengelola masalahmasalah bangsa)". Oleh karena itu institusi dari Governance meliputi tiga domain yaitu 
state (negara atau pemerintah), private sector (sektor swasta atau dunia usaha) dan society (masyarakat) yang saling berinteraksi dan menjalankan fungsinya masing-masing. (Sedarmayanti : 2003).

Menurut Dwiyanto (2005: 79-81) Governance menunjuk padapengertian bahwa kekuasaan tidak lagi semata-mata dimiliki atau menjadiurusan pemerintah.Governance menekankan pada pelaksanaan fungsigoverning secara bersama-sama oleh pemerintah dan institusiinstitusi lainyakni LSM, perusahaan swasta maupun warga negara.Meskipun perspektifGovernance mengimplikasikan terjadinya pengurangan peran pemerintah,pemerintah sebagai institusi tidak bisa ditinggalkan begitu saja.Pertanyaannya, bagaimana negara (pemerintah) menempatkan diri danbersikap ketika berlangsung proses governing dalam konteks Governance?Atau bagaimana pemerintah berperan dalam mengelola negara atau publik?

Setidaknya terdapat 6 prinsip yang ditawarkan yang dapat dijadikan acuan untuk menjawab pertanyaan yaitu: a) Dalam kolaborasi yang dibangun, negara (baca: pemerintah) tetap bermain sebagai figur kunci namun tidak mendominasi yang memiliki kapasitas untuk mengkoordinasi (bukan mobilisasi) aktor-aktor pada institusiinstitusi semi non-pemerintah untuk mencapai tujuan-tujuan public, b) Kekuasaan yang dimiliki negara harus ditransformasikan dari yang semula dipahami sebagai "kekuasaan atas" menjadi "kekuasaan untuk" menyelenggarakan kepentingan, memenuhi kebutuhan dan menyelesaikan masalah public, c) Negara, NGO, swasta dan masyarakat lokal merupakan aktor-aktor yang memiliki posisi dan peran yang saling menyeimbangkan - untuk tidak menyebut setara, d) Negara harus mampu mendesain ulang struktur dan kultur organisasinya agar siap dan mampu menjadi katalisator bagi institusi lainnya untuk menjalin sebuah kemitraan yang kokoh, otonom, dan dinamis, Negara harus melibatkan semua pilar masyarakat dalam proses kebijakan mulai dari formulasi, implementasi dan evaluasi kebijakan, serta pemberian layanan public, dan f) Negara harus mampu meningkatkan kualitas responsivitas, adaptasi dan akuntabilitas publik dalam penyelenggaraan kepentingan, pemenuhan kebutuhan dan menyelesaikan masalah publik.

Ada beberapa dimensi penting dari Governance, Dwiyanto (Nurhaeni : 2010) menjelaskan bahwa dimensi pertama dari Governance adalah dimensi kelembagaan, yang menjelaskan bahwa Governance merupakan sebuah sistem yang melibatkan banyak pelaku (multistakeholders), baik dari pemerintah maupun dari luar pemerintah dalam penyelenggaraan berbagai kegiatan untuk menanggapi masalah dan kebutuhan publik. Dimensi kedua dari Governance adalah nilai yang menjadi dasar dalam penggunaan kekuasaan.Nilai-nilai administrasi publik yang tradisional seperti efisiensi dan efektifitas telah bergeser menjadi nilai keadilan sosial, kebebasan dan kemanusiaan. Dimensi ketiga dari Governance adalah dimensi proses yang mencoba menjelaskan bagaimana berbagai unsur dan lembaga pemerintah memberi respon terhadap berbagai masalah publik yang muncul di lingkungannya. Dengan mengkaji Governance dari ketiga dimensi itu, maka Governance menjelaskan keterlibatan banyak pelaku dan jejaring pelaku dalam proses formulasi dan implementasi kebijakan yang dilakukan untuk mencapai tujuan dan atau menyelesaikan masalah bersama.

\section{Kemitraan Pemerintah- Swasta (Public- Private Partnership)}

Kemitraan Public Private Partnership (PPP) dilatarbelakangi oleh kesadaran pemerintah akan keterbatasannya dalam menyediakan pelayanan publik dan mengatasi masalah sosial. Selain itu, dengan adanya konsep good governance diharapkan peran serta aktor masyarakat dan swasta semakin maksimal dalam membantu upaya pembangunan yang dilakukan oleh pemerintah dan dengan adanya PPP ini diharapkan "shifting government role to be facilitator or enabler" (Ministry of National Development Planning/BAPPENAS, 2011).

Adapun pengertian Public-Private Partnership menurut World Bank (2014) mengatakan bahwa "Governments looking at options to improve performance of existing public assets and services in these sectors may consider a PPP as an alternative sector reform option to privatizing and establishing a regulatory regime".Dengan demikian 
pemerintah bukan lagi merupakan aktor tunggal yang bertanggungjawab atas permasalahan publik sehingga perlu dilakukannya privatisasi sebagai alternatif reformasi tata kelola pemerintahannya, sehingga kemitraan pemerintah-swasta ini dianggap sebagai strategi untuk melibatkan sektor swasta.

Menurut Yescombe (2007) mengatakan bahwa PPPs must be seen within the overall context of the public-sector reform movement known as 'New Public Management'(NPM), which encourages : 1. Decentralisation of government; 2. Separating responsibility for the purchase of public services from that of their provision; 3. Output or performancebased measurements of public services; 4. Contracting-out public services to private sector; dan 5. Privatisation of public service.

\section{Konsep Kondisi Sosial-Ekonomi Masyarakat}

Kondisi sosial ekonomi adalah suatu kedudukan yang diatur secara sosial dan menempatkan seseorang pada posisi tertentu dalam masyarakat, pemberian posisi itu disertai pula dengan seperangkat hak dan kewajiban yang harus dimainkan oleh si pembawa status (Sumardi : 2001). Kondisi sosial ekonomi menurut M. Sastropradja (2000) adalah keadaan atau kedudukan seseorang dalam masyarakat sekelilingnya. Manaso Malo (2001) juga memberikan batasan tentang kondisi sosial ekonomi yaitu, Merupakan suatu kedudukan yang diatur secara sosial dan menempatkan seseorang pada posisi tertentu dalam sosial masyarakat. Pemberian posisi disertai pula dengan seperangkat hak dan kewajiban yang harus dimainkan oleh si pembawa status.

Kondisi sosial ekonomi masyarakat ditandai adanya saling kenal mengenal antar satu dengan yang lain, paguyuban, sifat kegotong-royongan dan kekeluargaan. Kehidupan sosial masyarakat Desa Srigading terdiri dari interaksi sosial, nilai sosial, dan tingkat pendidikan, sedangkan gambaran kehidupan ekonomi masyarakat Desa srigading ini terdiri dari kepemilikan rumah tempat tinggal, luasnya tanah garapan atau tanah yang dimilikinya.
Mengenai kondisi sosial ekonomi, Yayuk Yuliati yang dikutip Zaenal Arifin (2002) menjelaskan kondisi sosial ekonomi sebagai kaitan antara status sosial dan kebiasaan hidup sehari-hari yang telah membudaya bagi individu atau kelompok di mana kebiasaan hidup yang membudaya ini biasanya disebut dengan culture activity, kemudian ia juga menjelaskan pula bahwa dalam semua masyarakat di dunia baik yang sederhana maupun yang kompleks, pola interaksi atau pergaulan hidup antara individu menunjuk pada perbedaan kedudukan dan derajat atau status kriteria dalam membedakan status pada masyarakat yang kecil biasanya sangat sederhana, karena disamping jumlah warganya yang relatif sedikit, juga orang-orang yang dianggap tinggi statusnya tidak begitu banyak jumlah maupun ragamnya.

Sementara W.S Winke (dalam Salim, 2002) menyatakan bahwa pengertian status sosial ekonomi mempunyai makna suatu keadaan yang menunjukan pada kemampuan finansial keluarga dan perlengkapan material yang dimilki, dimana keadaan ini bertaraf baik, cukup, dan kurang. Selanjutnyan Mubyarto (2001) berpendapat tinjauan sosial ekonomi penduduk meliputi aspek sosial, aspek sosial budaya, dan aspek Desa yang berkaitan dengan kelembagaan dan aspek peluang kerja. Aspek ekonomi Desa dan peluang kerja

berkaitan erat dengan masalah kesejahteraan masyarakat Desa. Kecukupan pangan dan keperluan ekonomi bagi masyarakat baru terjangkau bila pendapatan rumah tangga mereka cukup untuk menutupi keperluan rumah tangga dan pengembangan usaha-usahanya. Menurut pendapat Sajogyo (2001) dalam hubungan dengan pola berusaha tani, perbedaan status seseorang dalam masyarakat ditentukan oleh pola penguasaan lahan, modal, teknologi, dan luasnya lahan pemiliknya.

Menurut Mulyanto Sumardi dan Hans Dieter Evers (2002: 21) keadaan social ekonomi adalah suatu kedudukan yang secara rasional dan menetapkan seseorang pada posisi tertentu dalam masyarakat, pemberian posisi itu disertai pula dengan seperangkat hak dan kewajiban yang harus dimainkan oleh si pembawa status. Menurutnya pula ada ciri-ciri keadaan sosial ekonomi yaitu sebagai berikut : a. Lebih 
berpendidikan, b. Mempunyai status sosial yang ditandai dengan tingkat kehidupan, kesehatan, pekerjaan, dan pengenalan diri terhadap lingkungan, c. Mempunyai tingkat mobilitas ke atas lebih besar, d. Mempunyai ladang luas, e. Lebih berorientasi pada ekonomi komersial produk, f. Mempunyai sikap yang lebih berkenaan dengan kredit, dan g. Pekerjaan lebih spesifik.

Berdasarkan pendapat para ahli tersebut dapat dinyatakan bahwa kondisi social ekonomi adalah posisi individu dan kelompok yang berkenaan dengan ukuran rata-rata yang berlaku umum tentang pendidikan, pemilikan barang-barang, dan patisipasi dalam aktivitas kelompok dari komunitasnya, sedangkan kondisi sosial ekonomi kaitanya dengan status sosial ekonomi itu sendiri dengan kebiasaan hidup sehari-hari individu atau kelompok.

\section{METODE PENELITIAN}

Penelitian ini menggunakan metode penelitian kualitatif. Karakteristik penelitian kualitatif adalah datanya dinyatakan dalam keadaan kewajaran atau sebagimana adanya (natural setting) dengan tidak dirubah dalam bentuk simbol atau bilangan, sedangkan perkataan penelitian pada dasarnya berarti rangkaian kegiatan atau proses pengungkapan rahasia sesuatu yang belum diketahui dengan mempergunakan cara bekerja atau metode yang sistematis, terarah dan dapat dipertanggung jawabkan.

Informan dalam penelitian ini adalah para aktor dan pemangku kepentingan (stakeholders) peningkatan minat studi lanjut, meliputi: 1) Pemerintah: Seluruh jajaran SKPD terkait yang ada di lingkungan Pemerintah Kabupaten Pemalang, yaitu Dinas Pendidikan dan BAPPEKAB; 2) Swasta: pengusaha yang ada di Kabupaten Pemalang; dan 3) Para Pemerhati Penddikan, yaitu LSM yang konsen ke pendidikan, Dewan Pendidikan, BMPS (Badan Musyawarah Perguruan Swasta) Pemalang yang ditentukan secara purposive. Penetepan informan ini dengan pertimbangan bahwa para informan yang dipilih memahami permasalah yang menjadi fokusm penelitian.

Pengumpulan data dilakukan dengan tehnik dokumentasi, wawancara, dan observasi. Data yang dihimpun meliputi tingkat sosial ekonimi masyarakat, APK, dan bentuk kemitraan antara pemerintah dengan pihak swasta. Teknik analisis dalam penelitian ini menggunakan analisis interaktif. Keabsahan data adalah: "derajat kepercayaan atau kebenaran hasil penelitian sebagai standar dalam penelitian kualitatif" (Moleong, 2000). Sebagai penelitian kualitatif, hal memerlukan adanya standar untuk melihat derajad kepercayaan atau kebenaran terhadap hasil penelitian tersebut. Di dalam penelitian kualitatif standar tersebut sering disebut dengan keabsahan data. Lincoln dan Guba (1985), mengemukakan bahwa ada 4 kriteria yang digunakan untuk memeriksa keabsahan data, yaitu derajad kepercayaan (credibility), keteralihan (transferability), kebergantungan (dependability), dan kepastian (confirmability). Ini dilakukan dengan cara membandingkan data yang serupa dari sumber data yang berbeda.

\section{TEMUAN DAN PEMBAHASAN}

Dari data yang dihimpun penulis diperoleh informasi sebagai berikut: bahwa perekonomian Kabupaten Pemalang terus mengalami peningkatan dari tahun ke tahun. Hal ini ditunjukan dengan perkembangan PDRB atas dasar harga konstan Kabupaten Pemalang pada tahun 2016 sebesar 15,44 triliun rupiah atau tumbuh sebesar 5,38\% dibandingkan tahun 2015. Berdasarkan kontribusi sektor-sektor yang membentuk pertumbuhan ekonomi Kabupaten Pemalang, maka dapat diketahui sektor yang menunjukan pertumbuhan ekonomi tertinggi adalah sektor pengadaan listrik dan gas $8,99 \%$, sektor pertambangan dan penggalian sebesar 8,98\% dan sektor jasa keuangan dan asuransi yang tumbuh sebesar $8,51 \%$. PDRB perkapita merupakan salah satu indikator yang dapat digunakan untuk membandingkan tingkat kemakmuran daerah. PDRB perkapita diperoleh dengan membagi besaran nilai PDRB atas dasar harga konstan dengan penduduk pertengahan tahun pada tahun yang bersangkutan. Jadi besaran PDRB perkapita sangat tergantung dari besaran PDRB yang terbentuk dengan jumlah penduduk pada suatu tahun. Nilai PDRB perkapita atas dasar harga berlaku di Kabupaten Pemalang tahun 2016 yang dihasilkan sebesar Rp. 
20,72 juta, dengan jumlah penduduk pertengahan tahun sebesar 1.292.573 jiwa.

Dengan mengamati data tentang PDRB

penduduk sebesar 1.292.573 jiwa, maka dapat dinyatakan bahwa PDRB Kabupaten sebesar Rp.20,72 juta dengan jumlah

Pemalang masih rendah.

Tabel 1.1. PDRB Perkapita Menurut Lapangan Usaha 2015-2016

\begin{tabular}{lrr}
\hline \multirow{2}{*}{ Lapangan Usaha } & \multicolumn{2}{c}{ Tahun } \\
\cline { 2 - 3 } & \multicolumn{1}{c}{$\mathbf{2 0 1 5}$} & \multicolumn{1}{c}{$\mathbf{2 0 1 6}$} \\
\hline Jumlah penduduk pertengahan tahun (jiwa) & 1.288 .566 & 1.292 .573 \\
PDRB ADHB (juta rupiah) & $18.491 .385,49$ & $20.036 .515,72$ \\
PDRB ADHK (juta rupiah) & $14.673 .696,23$ & $15.463 .800,55$ \\
PDRB perkapita (juta/jiwa) & 14,35 & 15,50 \\
Pertumbuhan PDRB perkapita (persen) & 5,22 & 5,06 \\
\hline
\end{tabular}

Sumber: BPS Kabupaten Pemalang.

Jumlah penduduk Kabupaten Pemalang pada tahun 2016 tercatat sebesar 1.292.573 jiwa. Kecamatan Pemalang sebagai Ibukota Kabupaten memiliki jumlah penduduk terbesar yaitu sebesar 177.602 jiwa atau sekitar 13,74 persen dari total penduduk Kabupaten Pemalang. Kecamatan Comal memiliki kepadatan tertinggi yaitu sebesar 3.346 yang artinya, setiap $1 \mathrm{~km}^{2}$ didiami oleh sekitar 3.346 orang, diikuti oleh Kecamatan Taman dan Petarukan. Kondisi ketenagakerjaan di Kabupaten Pemalang ditandai dengan kenaikan yang cukup signifikan pada kelompok penduduk yang termasuk kategori angkatan kerja. Berdasarkan data Sakermas, BPS Provinsi Jawa Tengah jumlah angkatan kerja di
Kabupaten Pemalang pada tahun 2015 mengalami penurunan sebesar $7,63 \%$ dari 641.579 orang menjadi 592.613 orang. Pada tahun 2015 angkatan kerja yang menganggur sebanyak $6,52 \%$ dimana pada tahun sebelumnya di tahun 2014 angka pengangguran Kabupaten Pemalang sebesar 7,44\%. Kondisi ini menunjukan jumlah pengangguran mengalami penurunan yang cukup besar yaitu dari 47.759 di tahun 2014 menjadi 38.678 orang di tahun 2015.

Dengan mengamati data yang diperoleh tentang jumlah penduduk dan jumkah pengangguran, dapat dinyatakan bahwa pengangguran di Kabupaten Pemalang masih tinggi.

Tabel 1.2. Persentase Penduduk Umur 10 Tahun Ke Atas Menurut Pendidikan Tertinggi

\begin{tabular}{|c|c|c|c|c|c|c|c|c|c|}
\hline \multirow{2}{*}{$\begin{array}{c}\text { Jenis Pendidikan } \\
\text { Tertinggi }\end{array}$} & \multicolumn{3}{|c|}{2013} & \multicolumn{3}{|c|}{2014} & \multicolumn{3}{|c|}{2015} \\
\hline & $\mathbf{L}$ & $\mathbf{P}$ & $\mathrm{L}+\mathrm{P}$ & $\mathbf{L}$ & $\mathbf{P}$ & $\mathbf{L + P}$ & $\mathbf{L}$ & $\mathbf{P}$ & $L+P$ \\
\hline Tdk/BIm Pernah SD & 3,33 & 9,34 & 6,38 & 4,11 & 9,47 & 6,83 & 4,27 & 10,25 & 7,31 \\
\hline Tdk/Blm Tamat SD & 26,09 & 26,80 & 26,45 & 22,38 & 25,01 & 23,72 & 24,67 & 24,11 & 24,38 \\
\hline SD & 40,69 & 38,88 & 39,76 & 39,29 & 37,67 & 38,47 & 38,95 & 37,16 & 38,04 \\
\hline SMP & 15,42 & 14,59 & 15,00 & 19,31 & 15,18 & 17,21 & 17,33 & 15,49 & 16,40 \\
\hline SMA & 8,70 & 7,12 & 7,90 & 8,78 & 8,48 & 8,63 & 8,93 & 6,94 & 7,92 \\
\hline SMK & 3,86 & 1,73 & 2,78 & 3,75 & 1,66 & 2,68 & 2,48 & 2,63 & 2,56 \\
\hline D I & 0,38 & 0,04 & 0,21 & 0,15 & 0,40 & 0,28 & 0,64 & 0,28 & 0,46 \\
\hline D III & 0,49 & 0,06 & 0,27 & 0,59 & 0,31 & 0,42 & 0,64 & 0,62 & 0,63 \\
\hline$S 1 / 2$ & 1,04 & 1,44 & 1,25 & 1,64 & 1,82 & 1,73 & 2,09 & 2,52 & 2,30 \\
\hline
\end{tabular}

Sumber : Susenas 2013-2015 
Tabel 1.2 menjelaskan bahwa penduduk Pemalang berumur 10 tahun ke atas yang tidak/belum pernah sekolah dan tidak/belum menamatkan pendidikan di bangku Sekolah Dasar masih relatif tinggi yaitu 31,69\%. Penduduk yang berhasil menamatkan pendidikannya sampai Sekolah Dasar sebesar $38,04 \%$. Hal ini menunjukan bahwa penduduk dengan pendidikan hingga SD termasuk mereka yang belum pernah sekolah tercatat sebesar 69,73\%. Persentase yang cukup tinggi ini membawa konsekuensi antara lain upaya peningkatan kualitas SDM ataupun keterampilan mereka semakin kompleks. Masih sedikit penduduk yang menamatkan pendidikannya hingga jenjang perguruan tinggi yaitu hanya 3,39\%.

Data tentang prosentasi lulusan sekolah yang melanjutkan studi pada jenjang di atasnya, ini dapat dinyatakan bahwa minat studi lanjut di Kabupaten Pemalang masih rendah. Selain itu ditemukan pula data yang menyatakan bahwa rata-rata Lama Sekolah (MYS: Mean Years Schooling) penduduk di Kabupaten Pemalang masih sangat rendah hanya sebesar 6,05 sedangkan rata-rata pencapaian di Provinsi Jawa Tengah sudah mencapai 7,03. Dengan memadukan data prosentasi minat studi lanjut dan rata-rata lama sekolah dapat dinyatakan minat melanjutkan para lulusan sekolah ke jenjang yang lebih tinggi, sangat rendah. Hal ini sangat nampak jika diamati prosentasi yang melanjutkan ke perguruan tinggi.

Dengan mengamati tabel di atas dapat dinyatakan bahwa terdapat faktor pendukung dalam peningkatan APK atau minat studi lanjut, yaitu dilihat dari sisi umur para lulusan. Umur para lulusan sekolah berada pada umur-umur yang ideal untuk melanjutkan ke jenjang di atasnya. Artinya umur mereka belum kadaluwarsa atau melewati batas standar usia untuk menaljutkan studi ke jenjang di atasnya, misalnya dari sekolah dasar ke sekolah lanjutan, dan dari sekolah lanjutan ke perguruan tinggi.

Dari upaya menghimpun data tidak diperoleh data tentang berapa perusahaan yang sudah berkontribusi atau menyerahkan CSR nya kepada pemerintah untuk kepentingan meningkatkan minat melanjutkan studi pada para lulusan. Misalnya berupa pemberian bantuan biaya atau beasiswa bagi mereka melanjutkan ke perguruan tinggi.

\section{KESIMPULAN}

Kesimpulan yang didapat dari Kajian ini adalah sebagaoi berikut.

a. Indeks Pembangunan Manusia (IPM) di Kabupaten Pemalang lebih rendah dibandingkan dengan rata-rata Jawa Tengah dan Nasional, tetapi pertumbuhannya 5,58 selama tahun 2012-2016 ini tertinggi di Jawa Tengah $(4,12)$ dan bahkan di atas nasional $(3,66)$.

b. Rata-rata Lama Sekolah (RLS) Kabupaten Pemalang adalah sebesar 6,05 tahun lebih rendah dari Jawa Tengah sebesar 7,15 tahun.

c. Harapan Lama Sekolah Kabupaten Pemalang adalah sebesar 11,87 lebih rendah dari Provinsi Jawa Tengah yang sebesar 12,45.

d. Belum ditemukan berapa jumlah perusahaan dan berapa jumlah dana CSR yang disumbangkan ke pemerintah untuk kepentingan mendorong meningkatan jumlah lulusan yang melnjutkan ke jenjang yang lebih tinggi, misalnya berupa beasiswa bagi yang melanjutkan ke perguruan tinggi.

\section{SARAN}

Sesuai dengan temuan dan pembahasan dalam kajian ini, saran yang relevan untuk ditindaklanjuti sebagai berikut.

1. Untuk meningkatkan daya beli masyarakat agar mampu membiayai studi lanjut anak-anaknya maka perlu intervensi pemerintah kabupaten dalam hal : peningkatan modal/investasi; peningkatan kualitas tenaga kerja; pengendalian harga barang; pengembangan perilaku konsumen.

2. Mendorong tumbuhnya iklim usaha yang kondusif untuk meningkatkan investasi/penanaman modal. Dengan investasi atau penanaman modal secara signifikan dapat mendorong akselerasi pembangunan secara luas yang dapat meningkatkan produksi barang dan jasa, dan mengurangi pengangguran sehingga mampu meningkatkan 
pendapatan

masyarakat.

Keberadaannya perlu didukung melalui kemudahan dalam pelayanan perijinan dan ketersediaan infrastruktur yang memadai.

3. Insentif biaya untuk meningkatkan mutu dan kualitas tenaga kerja. Dengan insentif biaya dapat dilakukan melalui investasi pemerintah dalam pendidikan dan ketrampilan khusus sesuai dengan kebutuhan pasar kerja dan kesempatan kerja melalui peningkatan sarana dan prasarana pendidikan.

4. Untuk mendorong tingginya jumlah lulusan yang berminat melanjutkan ke perguruan tinggi, maka perlu adanya kerja sama pemerintah kabupaten dengan perguruan tinggi negeri terdekat untuk mebuka program vokasi di Kabupaten Pemalang.

\section{DAFTAR PUSTAKA}

Bae, J., \& Rowley, C. (2004). Macro and micro approaches in human resource development: context and content in South Korea. Journal of World Business, 39, 349-361.

Burhan, B. (2003). Analisis data penelitian kualitatif: Pemahaman filosofis dan metodologis ke arah penguasaan model aplikasi. Jakarta: PT. Raja Grafindo Persada.

Brown, A. W., Adams, J. D., \& Amjad, A. A. (2007). The relationship between human capital and time performance in project management : A path analysis. International Journal of Project Management, 25(1), 77-89.

Chirkov, V., Vansteenkiste, M., Tao, R., \& Lynch, M. (2007). The role of selfdetemined motivation and goals for study abroad in the adaptation of international students. International Journal of Intercultural Relations, 31(2), 199-222.

Damanhuri, D. S. (2004). SDM Indonesia dalam persaingan global. Sinar Harapan: 13 Juni 2003.

Datta, D. K., Guthrie, J. P., \& Wright, P. M. 2005. Human resource management and labor productivity: Does industry matter? Academy of Management Journal, 48(1), 135-145.

Dimov, D. P., \& Shepherd, D. A. (2005). Human capital theory and venture capital firms: Exploring "home runs" and "strike outs". Journal of Business Venturing, 20(1), 1-21.

Jones, G. R. (2004). Organizational theory, design and change: Text and cases. Upper Sadle River : Prentice-Hall International Inc.

Karatepe, O. M., Uludag, O., Menevis, I., \& Baddar, L. (2006). The effects of selected individual characteristics on frontline employee performance and job satisfaction. Tourism Management, 27(4), 547-560.

Kovel-Jarboe, P. (2005). The changing contexs of higher education and four possible futures for distance education. University of Minnesota.

Lanzi, D. (2007). Capabilities, human capital and education. The Journal of SocioEconomics, 30, 1-12.

Lievens, F., Van Dam, K., \& Anderson, K. (2002). Recent trends and challenges in personnel selection. Personnel Review, 31(5), 580-600.

Lin, B. W. (2007). Information technology capabilitiy and value creation: Evidence from the US banking industry. Technology In Society, 29(2007), 93-106.

Mangundayao, A. B., Briones, S. J., \& Mefragata, J. D. (2003). Sustaining Techinicion Education in the Age of Globalization. Research Report: Technology University of the Philippines.

Moleong, L. J. (1999). Metodologi penelitian kualitatif. Bandung: PT Remaja Rosdakarya.

Naisbitt, J., \& Aburdene, P. (1990). Sepuluh langkah baru untuk tahun 1990-an Megatrends 2000. Jakarta: Binarupa Aksara.

Pidarta, M. (2000). Landasan kependidikan, stimulus ilmu pendidikan bercorak Indonesia. Jakarta: Penerbit Rineka Cipta. Sahney, S., Banwet, D. K., \& Karunes, S. (2003). Enhancing quality in education: Application of quality function deployment - an industry perspective. Work Study, 52(6), 297-309.

Sajogyo. (2005). Sosiologi pedesaan. Yogyakarta: Gadjah Mada Press.

Salladien. (2002). Alternatif model pendidikan berorientasi dunia kerja sebagai upaya menghadirkan SDM berkompetensi di Era Otonomi Daerah. Makalah yang disampaikan pada Seminar 
Nasional Perguruan Tinggi Se-Jawa Timur - Universitas Brawijaya Tgl. 18-19 Oktober 2002.

Setyanto, R. P. (2004). Pengukuran human capital: Peluang bagi departemen SDM untuk berperan sebagai strategic business partner. Majalah Usahawan Indonesia, 10(XXXIII), 18-22.

Todaro, M. P., \& Smith, S. C. (2003). Pembangunan Ekonomi di Dunia Ketiga. Jakarta : Erlangga.

van der Colf, L. (2004). A new paradigm for business education: The role of the business educator and business school. Management Decision, 42(3/4), 499-507.

Wronka, I., \& Pawlinksa-Chmara, R. (2006). Childcare, height and BMI among female Polish university students, 2005. Economics and Human Biology, 5(3), 1-8.

Yescombe, E.R. (2007). Public-private partnership, principles of policy and finance. London: Elsevier Ltd. 
Mashudi, et al. / Minat Studi Lanjut: Tinjauan Kritis dari Sudut ... 